\title{
Proton tunnelling and promoting vibrations during the oxidation of ascorbate by ferricyanide?
}

Cite this: Phys. Chem. Chem. Phys., 2014, 16, 2256

Received 13th December 2013, Accepted 2nd January 2014

DOI: $10.1039 / c 3 c p 55131 h$

www.rsc.org/pccp

\author{
Shaun M. Kandathil, Max D. Driscoll, Rachel V. Dunn, Nigel S. Scrutton* and \\ Sam Hay*
}

\begin{abstract}
A combination of the temperature- and pressure-dependencies of the kinetic isotope effect on the proton coupled electron transfer during ascorbate oxidation by ferricyanide suggests that this reference reaction may exploit vibrationally assisted quantum tunnelling of the transferred proton.
\end{abstract}

The catalytic effect of enzymes - the rate enhancement relative to the uncatalysed rate $\left(k_{\text {cat }} / k_{\text {uncat }}\right)$ - is often unparalleled, yet the precise origin(s) of this catalytic effect remain unresolved. A major problem ${ }^{1}$ remains the identification of good reference reactions that can be used to study the uncatalysed reaction. ${ }^{2-4}$ One class of potential reference reactions involve the oxidation of L-ascorbate $\left(\mathrm{HAsc}^{-} \text {; vitamin } \mathrm{C}\right)^{5-12}$ and are similar to the reactions catalysed by ascorbate peroxidase enzymes ${ }^{13}$ and cytochrome $b_{561}$ proteins. ${ }^{14}$ In aqueous solution, ascorbate can be oxidised in two sequential 1-electron transfer reactions (Scheme 1; DHA is dehydroascorbic acid) by oxidants including ferricyanide $\left(\left[\mathrm{Fe}(\mathrm{CN})_{6}\right]^{3-}\right) \cdot{ }^{5,11,12}$

During the first step of the reaction $\left(k_{1}\right)$, the electron transfer from ascorbate to ferricyanide appears to be kinetically-coupled to the proton transfer from ascorbate to solvent (i.e. a protoncoupled electron transfer; PCET), as modest solvent kinetic isotope effects (KIEs) have been observed on ferricyanide reduction. ${ }^{7,11,12}$

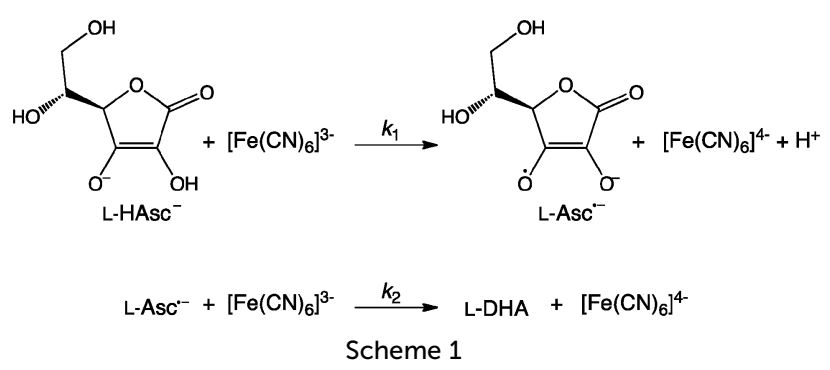

Manchester Institute of Biotechnology (MIB) and Faculty of Life Sciences, University of Manchester, 131 Princess St., Manchester, UK M1 7DN. E-mail: nigel.scrutton@manchester.ac.uk,sam.hay@manchester.ac.uk; Fax: +44 (0)161 3065201; Tel: +44 (0)161 3065141
Under certain solvent conditions, the magnitude of the observed KIE at room temperature is larger than the semi-classical limit of $\sim 7$, suggesting that nuclear quantum mechanical tunnelling (NQMT) of the transferred proton occurs during the PCET reaction. ${ }^{15}$ In addition, the temperature dependence of the $\operatorname{KIE}\left(\Delta E_{\mathrm{a}}\right.$ or $\left.\Delta \Delta H^{\ddagger}\right)$ varies with solvent composition and, in some cases is quite large $\left(\Delta E_{\mathrm{a}} \sim 10 \mathrm{~kJ} \mathrm{~mol}^{-1}\right){ }^{9,12}$ Strongly temperature-dependent KIEs have been used as evidence to support the promoting vibrations hypothesis, where $\mathrm{H}$ transfer is coupled to molecular vibration(s) between the donor and acceptor atoms that modulate the rate of $\mathrm{H}$-transfer by transiently reducing the apparent classical barrier height and/or width.,16-18

Recent studies of PCET during ascorbate oxidation reactions have suggested that the degree of NQMT during this reaction is variable and dependent on solvent composition and/or the oxidant. $^{9-12}$ In these cases, NQMT was inferred from either the magnitude of the KIE (KIE $\gg 7$ ) or the Arrhenius prefactor ratio $\left(A^{\mathrm{H}} / A^{\mathrm{D}} \ll 1\right) .{ }^{8,10}$ A model PCET system where the degree of NQMT and the temperature dependence of the KIE varies would allow more rigorous testing of the promoting vibration hypothesis and the possibility that NQMT is catalytic. ${ }^{1}$ However, further evidence that the solvent modulates the degree of NQMT during these reactions is desirable.

In the absence of NQMT, KIEs on H-transfers arise due to differences in vibrational zero-point energy and thus the stretching frequency of the transferred $\mathrm{H}, \mathrm{D}$ or $\mathrm{T} .{ }^{15}$ Generally, $\mathrm{C}-\mathrm{H}$ stretches are insensitive to several kbar changes in pressure (the typical experimental range; 1 bar $=100 \mathrm{kPa}),{ }^{19,20}$ so pressure dependent KIEs have been used as evidence for the involvement of NQMT during $\mathrm{H}$ transfer. ${ }^{21,22}$ In this communication, we use both variable temperature and hydrostatic pressure $^{23}$ to further characterise the ascorbate-ferricyanide reaction and to determine whether it is possible to alter the degree of NQMT by altering the solvent composition; in this case, by the addition of tetraethylammonium chloride (TEA), a salt that has been shown to significantly increase both the magnitude and temperature dependence of the KIE on this reaction. $^{12}$ 
While both ascorbic acid $\left(\mathrm{H}_{2} \mathrm{Asc}\right)$ and ascorbate $\left(\mathrm{HAsc}^{-}\right)$ reduce ferricyanide, they do so with significantly different rate constants and associated thermodynamic parameters. ${ }^{5}$ As we will focus on the more physiologically-relevant ascorbate reaction, we chose to work in buffered solution at $\mathrm{pH} 6.0, \dagger$ where ascorbate is relatively stable ${ }^{24}$ and the concentration of ascorbic acid negligible; the $\mathrm{p} K_{\mathrm{a}}$ of the $\mathrm{H}_{2} \mathrm{Asc}$ deprotonation to $\mathrm{HAsc}^{-}$is 4.1. ${ }^{5}$ Further, as the corresponding reaction volume is reported to be $-9.6 \mathrm{~cm}^{3} \mathrm{~mol}^{-1,5}$ the $\mathrm{p} K_{\mathrm{a}}$ of ascorbic acid decreases with increasing pressure $\left(\Delta \ln K_{\mathrm{a}}=-\Delta V_{\mathrm{a}} / R T\right)$, so the concentration of ascorbic acid will be further diminished at elevated pressures.

The temperature- (Fig. 1) and pressure- (Fig. 2) dependencies of ferricyanide reduction by ascorbate were determined using stopped-flow spectrometry by monitoring the loss of ferricyanide absorbance at $420 \mathrm{~nm}$. The PCET rate constant, $k_{1}$ (Scheme 1) was determined by: $k_{1}=k_{\text {obs }} / 2\left[\mathrm{HAsc}^{-}\right]^{5,11,12}$ and these data were fit to eqn (1) or (2), with the resulting thermodynamic parameters given in Table 1 .

$$
\begin{gathered}
k(T)=\left(k_{\mathrm{B}} T / h\right) \exp \left(\Delta S^{\ddagger} / R\right) \exp \left(-\Delta H^{\ddagger} / R T\right) \\
k(p, T)=k_{0}(T) \exp \left(-\Delta V^{\ddagger}(T) / R_{\mathrm{p}} T\right)
\end{gathered}
$$

The observed activation parameters $\left(\Delta H^{\ddagger \mathrm{H}}, \Delta S^{\ddagger \mathrm{H}}\right.$ and $\left.\Delta V^{\ddagger \mathrm{H}}\right)$ are generally in good agreement with previous reports of similar reaction conditions, ${ }^{5,9,12}$ suggesting that the presence of $50 \mathrm{mM}$ MES buffer $\dagger$ does not significantly perturb the reaction.

The reactions were repeated in buffered $\mathrm{D}_{2} \mathrm{O}$ solutions in order to determine the solvent KIE on the PCET during the

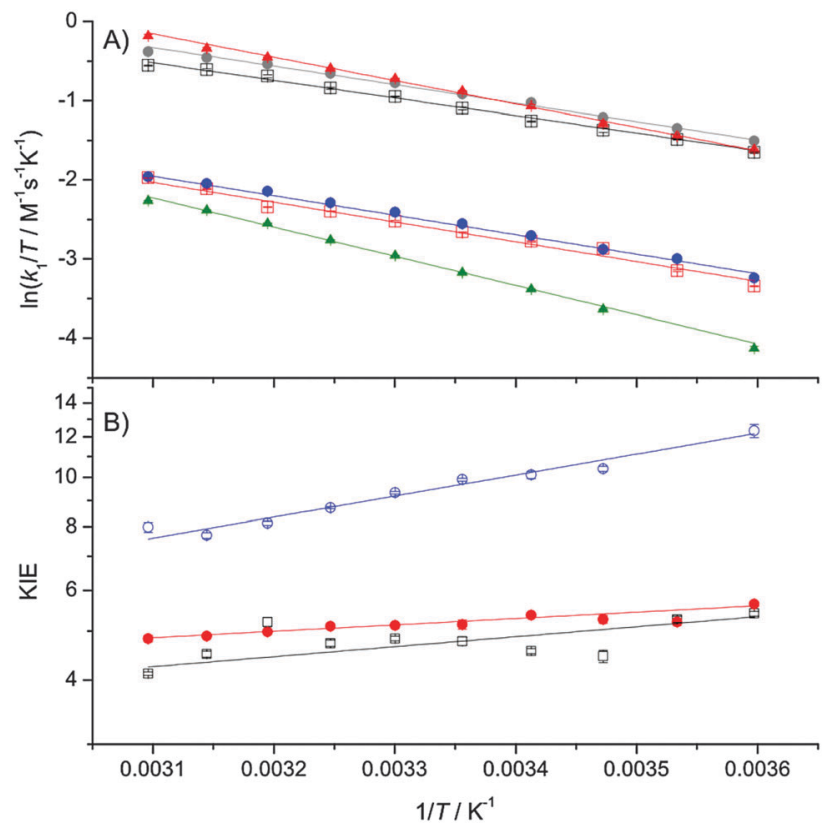

Fig. 1 Eyring plots of $k_{1}(\mathrm{~A})$ and the temperature dependence of the KIE on $k_{1}$ (B) fit to eqn (1). Key: (A) black squares, $5 \mathrm{mM} \mathrm{HAsc}^{-}, \mathrm{H}_{2} \mathrm{O}$; red squares, $5 \mathrm{mM} \mathrm{HAsc}^{-}, \mathrm{D}_{2} \mathrm{O}$; grey circles, $10 \mathrm{mM} \mathrm{HAsc}^{-}, \mathrm{H}_{2} \mathrm{O}$; blue circles, $10 \mathrm{mM} \mathrm{HAsc}^{-}, \mathrm{D}_{2} \mathrm{O}$; red triangles, $10 \mathrm{mM} \mathrm{HAsc}^{-}, 0.85 \mathrm{M} \mathrm{TEA} \mathrm{H}_{2} \mathrm{O}$; green triangles, $10 \mathrm{mM} \mathrm{HAsc}^{-}, 0.85 \mathrm{M} \mathrm{TEA} \mathrm{D}_{2} \mathrm{O}$. (B) Black squares, $5 \mathrm{mM} \mathrm{HAsc}$; red circles, $10 \mathrm{mM}$ HAsc; blue circles, $10 \mathrm{mM}$ HAsc, $0.85 \mathrm{M}$ TEA.

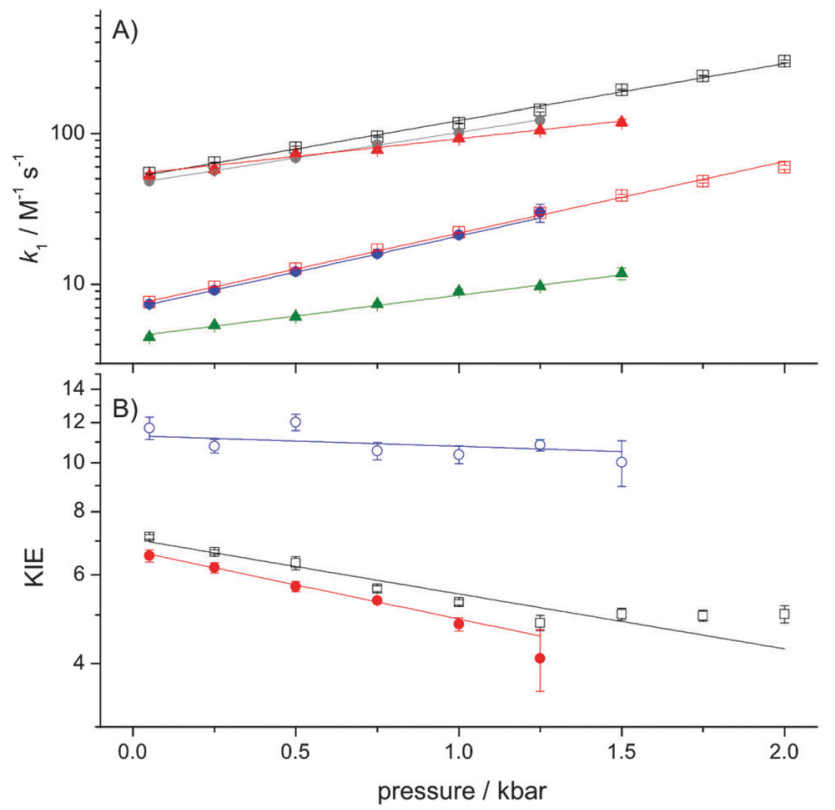

Fig. 2 The pressure dependence of $k_{1}(\mathrm{~A})$ and the KIE on $k_{1}(\mathrm{~B})$ at $278 \mathrm{~K}$. The data are fit to eqn (2) and the experimental conditions and symbol/ colour scheme is the same as used in Fig. 1. Experiments were performed at $278 \mathrm{~K}$ in order to prevent significant ascorbate degradation during the relatively long lifetime of the experiment, which was typically 1-2 hours.

Table 1 Kinetic and thermodynamic parameters

\begin{tabular}{llll}
\hline $\left.\mathrm{HAsc}^{-}\right](\mathrm{mM})$ & 5 & 10 & 10 \\
{$[\mathrm{TEA}]^{a}(\mathrm{M})$} & 0 & 0 & 0.85 \\
$k_{1}^{\mathrm{H}}\left(\mathrm{M}^{-1} \mathrm{~s}^{-1}\right)^{b}$ & $99 \pm 2$ & $119 \pm 2$ & $123 \pm 1$ \\
$k_{1}^{\mathrm{H}} / k_{1}^{\mathrm{D}}$ & $4.8 \pm 0.1$ & $5.1 \pm 0.1$ & $9.9 \pm 0.1$ \\
$\Delta H^{\ddagger \mathrm{H}}\left(\mathrm{kJ} \mathrm{mol}^{-1}\right)$ & $18.4 \pm 0.5$ & $19.4 \pm 0.4$ & $24.5 \pm 0.4$ \\
$\Delta \Delta H^{\ddagger}\left(\mathrm{kJ} \mathrm{mol}^{-1}\right)$ & $2.4 \pm 1.6$ & $1.1 \pm 0.9$ & $6.1 \pm 0.9$ \\
$\Delta S^{\ddagger \mathrm{H}}(\mathrm{J} \mathrm{mol}$ & -1 \\
$\Delta \Delta S^{\ddagger}\left(\mathrm{J} \mathrm{mol}^{-1} \mathrm{~K}^{-1}\right)$ & $-145 \pm 2$ & $-140 \pm 1$ & $-123 \pm 1$ \\
& $-5 \pm 5$ & $-10 \pm 3$ & $2 \pm 3$ \\
$k_{1,0}^{\mathrm{H}}\left(\mathrm{M}^{-1} \mathrm{~s}^{-1}\right)^{c}$ & $51.2 \pm 0.8$ & $46.7 \pm 0.3$ & $53.7 \pm 1.8$ \\
$k_{1,0}^{\mathrm{H}} / k_{1,0}^{\mathrm{D}}$ & $7.0 \pm 0.2$ & $6.7 \pm 0.1$ & $11.8 \pm 0.6$ \\
$\Delta V^{\ddagger \mathrm{H}}\left(\mathrm{cm}^{3} \mathrm{~mol}^{-1}\right)$ & $-20.0 \pm 0.4$ & $-18.0 \pm 0.2$ & $-12.5 \pm 0.9$ \\
$\Delta \Delta V^{\ddagger}\left(\mathrm{cm}^{3} \mathrm{~mol}^{-1}\right)$ & $+5.3 \pm 0.7$ & $+7.5 \pm 0.4$ & $+1.8 \pm 1.4$
\end{tabular}

The parameters are derived by fitting the data in Fig. $1 \mathrm{~A}$ and $2 \mathrm{~A}$ to eqn (1) and (2), respectively. The quoted errors are standard errors determined during the data fitting. ${ }^{a}$ The tetraethylammonium chloride (TEA) concentration of $0.85 \mathrm{M}$ was chosen to be $>0.5 \mathrm{M}$ (where the effect is saturated ${ }^{12}$ ) and still in solution under all experimental conditions used in our study. ${ }^{b} k_{1}$ was measured at $298 \mathrm{~K}^{c}{ }^{c} k_{1,0}, \Delta V^{\ddagger \mathrm{H}}$ and $\Delta \Delta V^{\ddagger}$ were determined at $278 \mathrm{~K} . \Delta \Delta H^{\ddagger}=\Delta H^{\ddagger \mathrm{D}}-\Delta H^{\ddagger \mathrm{H}} ; \Delta \Delta S^{\ddagger}=\Delta S^{\ddagger \mathrm{D}}-\Delta S^{\ddagger \mathrm{H}}$; $\Delta \Delta V^{\ddagger}=\Delta V^{\ddagger \mathrm{H}}-\Delta V^{\ddagger \mathrm{D}}$.

reaction (Fig. 1 and 2; Table 1). The $\mathrm{pH}$ of the $\mathrm{D}_{2} \mathrm{O}$ solutions $\left(\mathrm{pH}^{*}\right.$ 6.0, $\mathrm{pD}$ 6.4) was chosen to offset the change in ascorbate $\mathrm{p} K_{\mathrm{a}}$ caused by deuteration. ${ }^{25}$ The reactions were performed with both $5 \mathrm{mM}$ and $10 \mathrm{mM}$ ascorbate (both in vast excess of ferricyanide) to confirm that the reaction is both strictly second-order, and that the KIE is independent of ascorbate concentration.

Like previous reports, ${ }^{9,12}$ in the absence of TEA the observed KIE on $k_{1}$ is within the semi-classical limit $(<7)$ at $25^{\circ} \mathrm{C}$ and is only marginally temperature dependent. However, while the 
pressure dependence of $k_{1}^{\mathrm{H}}\left(\Delta V^{\ddagger \mathrm{H}}\right)$ is not remarkable, and similar to previous reports, ${ }^{5}$ we found the KIE to be significantly pressure-dependent $\left(\left|\Delta \Delta V^{\ddagger}\right| \gg 0\right.$; Table 1). As the pressure dependence of a KIE is a diagnostic of NQMT, ${ }^{21,22}$ these data provide compelling evidence for proton tunnelling from $\mathrm{HAsc}^{-}$ to solvent during the PCET reaction.

Like previous reports, ${ }^{12}$ in the presence of high concentrations of TEA, the magnitude of the KIE becomes larger than the semiclassical limit, suggesting that NQMT plays a significant role during the PCET. ${ }^{15}$ As the difference in activation enthalpy is significantly increased, while the pressure dependencies of both $k_{1}$ and the KIE are significantly reduced in the presence of TEA (Table 1), it would appear that TEA may influence the (vibrational) coupling of the $\mathrm{H}$-transfer to the environment - i.e. the apparent promoting vibration(s) that give rise to the temperaturedependence of the KIE. ${ }^{23,26}$

We recently determined the pressure- and temperaturedependence of the large KIE on proton transfer catalysed by aromatic amine dehydrogenase (AADH). In this case, the pressure dependence of the KIE was found to vary with temperature ${ }^{27}$ and we concluded that while the AADH reaction clearly employs significant NQMT, ${ }^{28}$ the pressure-dependence of this KIE is not a good diagnostic of NQMT in this reaction. In the presence of TEA, the ascorbate-ferricyanide reaction behaves in a similar manner: both the magnitude of the KIE and $\Delta \Delta H^{\ddagger}$ suggest that significant NQMT is involved, yet $\Delta \Delta V^{\ddagger}$ is negligible (Table 1). More generally, the data in the present study provide further evidence that while strongly pressure-dependent KIEs are likely to arise as a result of NQMT, the absence of a pressure dependence of a KIE on $\mathrm{H}$ transfer is not evidence for a lack of NQMT during the reaction.

Taken together, the temperature and pressure dependencies of the KIE on the ascorbate-ferricyanide reaction suggest that NQMT plays a role during the reaction both in the presence (exalted KIE and increased $\Delta \Delta H^{\ddagger}$ ) and absence of TEA (exalted $\left.\Delta \Delta V^{\ddagger}\right)$. Further, the temperature dependence of the reaction in the presence of TEA is supportive evidence for the role of 'promoting vibrations'.,16

There are few examples of small molecule systems that manifest strongly temperature-dependent KIEs. It has been suggested that the unusual temperature dependencies of the KIE on quinol oxidation ${ }^{29,30}$ may arise due to the involvement of donor-acceptor vibrational modes (i.e. promoting vibration(s)) as well as excited vibronic states in the Marcus inverted region. ${ }^{31}$ In the case of the ascorbate-ferricyanide reaction, the PCET is likely to occur in a (transient) collisional complex formed between ascorbate and ferricyanide, as the reaction is secondorder. Also, as the proton acceptor is likely to be solvent water, the nature of any persistent donor-acceptor vibrational modes will be very different to those promoting vibrations proposed to play a role during enzyme-catalysed reactions. ${ }^{1,16-18}$ It is noteworthy that both the magnitude and temperature dependence of the KIE on the ascorbate-ferricyanide reaction is modulated by changes in solvent composition (Table 1 and e.g. ref. 9-12). The reorganisation energy is sensitive to the solvent composition, and if the PCET reaction involves significant contribution from donor and/or acceptor excited vibronic states, then the KIE may be significantly temperature dependent (as is the case when TEA is added; Fig. 1) and sensitive to the solvent reorganisation. ${ }^{31}$ The ascorbate-ferricyanide reaction should be tractable for further theoretical and/or computational analysis to determine the precise origins of the magnitude and temperature dependence of the KIE on its PCET reaction.

In summary, the combination of the temperature- and pressure-dependencies of the KIE on the ascorbate-ferricyanide reaction have demonstrated that NQMT appears to play a role in the PCET during this reaction, both in the presence and absence of TEA, and is likely to be a general feature of the PCET during ascorbate oxidation. Significantly, the combined use of pressure and temperature allows one, in this case, to uncover NQMT contributions, which are not apparent when only looking at the magnitude or temperature-dependence of the KIE. Also, as the temperature dependence of the KIE is readily modulated by solvent composition, ${ }^{9-12}$ this is an ideal reference reaction for related studies of tunnelling and the potential involvement of promoting vibrations in related enzyme systems.

S.H. is a Biotechnology and Biological Sciences Research Council (BBSRC) David Phillips Fellow. N.S.S. is a Royal Society Wolfson Research Merit Award holder and an Engineering and Physical Sciences Research Council Established Career Fellow in Catalysis.

\section{Notes and references}

$\dagger$ All materials were purchased from Sigma-Aldrich except $\mathrm{D}_{2} \mathrm{O}$, which was purchased from Goss Scientific Equipment Ltd. $\mathrm{L}-\mathrm{H}_{2}$ Asc solutions were prepared on the day of use and their concentration was determined spectrophotometrically in $\sim 1 \mathrm{mM} \mathrm{HCl}$ by $\varepsilon=7.5 \mathrm{mM}^{-1} \mathrm{~cm}^{-1}$ at $245 \mathrm{~nm} .{ }^{24}$ All measurements were performed with $0.1 \mathrm{mM} \mathrm{K}_{3}\left[\mathrm{Fe}(\mathrm{CN})_{6}\right]$, $0.5 \mathrm{mM} \mathrm{Na} \mathrm{N}_{2}$ EDTA and $50 \mathrm{mM}$ MES (2-( $N$-morpholino)ethanesulfonic acid; $\left.\mathrm{p} K_{\mathrm{a}}=6.15\right)$ buffer, $\mathrm{pH}$ or $\mathrm{pH}^{*}$ 6.0. MES was chosen due to its relatively low temperature $\left(\Delta \mathrm{p} K_{\mathrm{a}} / T=-0.011 \mathrm{~K}^{-1}\right)^{32}$ and pressure $\left(\Delta V^{0}=+3.9 \mathrm{~cm}^{3} \mathrm{~mol}^{-1}\right)^{33}$ coefficients. Temperature-dependent stopped-flow experiments were performed with an Applied Photophysics (Leatherhead, UK) SX.18MV-R stopped-flow spectrophotometer. High-pressure experiments were performed using a Hi-Tech Scientific HPSF- 56 highpressure stopped-flow spectrophotometer (TgK Scientific, Bradford on Avon, UK). In both cases, the reaction was monitored at $420 \mathrm{~nm}$ and fit to a single or double (to account for a minor slow-phase)-exponential function to determine $k_{\text {obs }}$.

1 S. Hay and N. S. Scrutton, Nat. Chem., 2012, 4, 161-168.

2 A. Radzicka and R. Wolfenden, Science, 1995, 267, 90-93.

3 K. M. Doll, B. R. Bender and R. G. Finke, J. Am. Chem. Soc., 2003, 125, 10877-10884.

4 D. T. Major, A. Heroux, A. M. Orville, M. P. Valley, P. F. Fitzpatrick and J. L. Gao, Proc. Natl. Acad. Sci. U. S. A., 2009, 106, 20734-20739.

5 N. Kagayama, M. Sekiguchi, Y. Inada, H. D. Takagi and S. Fanahashi, Inorg. Chem., 1994, 33, 1881-1885.

6 D. Vuina, V. Pilepic, D. Ljubas, K. Sankovic, I. Sajenko and S. Ursic, Tetrahedron Lett., 2007, 48, 3633-3637.

7 I. Sajenko, V. Pilepic, C. J. Brala and S. Ursic, J. Phys. Chem. A, 2010, 114, 3423-3430.

8 C. J. Brala, V. Pilepic, I. Sajenko, A. Karkovic and S. Ursic, Helv. Chim. Acta, 2011, 94, 1718-1731. 
9 A. Karkovic, C. J. Brala, V. Pilepic and S. Ursic, Tetrahedron Lett., 2011, 52, 1757-1761.

10 I. Sajenko, V. Pilepic and S. Ursic, Z. Phys. Chem., 2011, 225, 805-820.

11 C. J. Brala, A. Karkovic, K. Klepac, A. M. Vucinovic, V. Pilepic and S. Ursic, Z. Phys. Chem., 2011, 225, 821-841.

12 C. J. Brala, A. Karkovic, I. Sajenko, V. Pilepic and S. Ursic, Z. Phys. Chem., 2012, 226, 29-46.

13 E. L. Raven, L. Lad, K. H. Sharp, M. Mewies and P. C. Moody, Biochem. Soc. Symp., 2004, 27-38.

14 D. Njus, M. Wigle, P. M. Kelley, B. H. Kipp and H. B. Schlegel, Biochemistry, 2001, 40, 11905-11911.

15 R. Bell, The Tunnel Effect in Chemistry, Chapman and Hall, 1980.

16 Z. D. Nagel and J. P. Klinman, Chem. Rev., 2010, 110, PR41-PR67.

17 S. D. Schwartz, Top. Curr. Chem., 2013, 337, 189-208.

18 S. Hammes-Schiffer, Biochemistry, 2013, 52, 2012-2020.

19 N. S. Isaacs, in Isotope Effects in Organic Chemistry, ed.

E. Buncel and C. C. Lee, Elsevier, London, 1984, pp. 67-105.

20 D. B. Northrop, Philos. Trans. R. Soc., B, 2006, 361, 1341-1349.

21 N. S. Isaacs, K. Javaid and E. Rannala, Nature, 1977, 268, 372.

22 D. B. Northrop, J. Am. Chem. Soc., 1999, 121, 3521-3524.
23 S. Hay, M. J. Sutcliffe and N. S. Scrutton, Proc. Natl. Acad. Sci. U. S. A., 2007, 104, 507-512.

24 R. M. C. Dawson, D. C. Elliot, W. H. Elliot and K. M. Jones, Data for biochemical research, Oxford University Press, Oxford, 3rd edn, 1986.

25 A. Krezel and W. Bal, J. Inorg. Biochem., 2004, 98, 161-166.

26 S. Hay and N. S. Scrutton, Biochemistry, 2008, 47, 9880-9887.

27 S. Hay, L. O. Johannissen, P. Hothi, M. J. Sutcliffe and N. S. Scrutton, J. Am. Chem. Soc., 2012, 134, 9749-9754.

28 L. Masgrau, A. Roujeinikova, L. O. Johannissen, P. Hothi, J. Basran, K. E. Ranaghan, A. J. Mulholland, M. J. Sutcliffe, N. S. Scrutton and D. Leys, Science, 2006, 312, 237-241.

29 S. Nagaoka, M. Inoue, C. Nishioka, Y. Nishioku, S. Tsunoda, C. Ohguchi, K. Ohara, K. Mukai and U. Nagashima, J. Phys. Chem. B, 2000, 104, 856-862.

30 J. L. Cape, M. K. Bowman and D. M. Kramer, J. Am. Chem. Soc., 2005, 127, 4208-4215.

31 M. K. Ludlow, A. V. Soudackov and S. Hammes-Schiffer, J. Am. Chem. Soc., 2009, 131, 7094-7102.

32 N. E. Good, G. D. Winget, W. Winter, T. N. Connolly, S. Izawa and R. M. M. Singh, Biochemistry, 1966, 5, 467-477.

33 Y. Kitamura and T. Itoh, J. Solution Chem., 1987, 16, 715-725. 